\title{
Detecção de Pantoea ananatis em sementes de milho
}

\author{
Morgana Coelho Mamede ${ }^{1} \oplus$, Nilvanira Donizete Tebaldi ${ }^{\circledR} \odot$
}

\begin{abstract}
${ }^{1}$ Mestre em Agronomia, Instituto de Ciências Agrárias, da Universidade Federal de Uberlândia, Av. Amazonas s/n, Bloco 2E-191, Campus Umuarama, CEP 38.400-902, Uberlândia, MG, Brasil. Parte da Dissertação de Mestrado. ${ }^{2}$ Professora Associada do Instituto de Ciências Agrárias, da Universidade Federal de Uberlândia, Av. Amazonas s/n, Bloco 2E-191, Campus Umuarama, CEP 38.400-902, Uberlândia, MG, Brasil. Autor para correspondência: Nilvanira Donizete Tebaldi (nilvanira.tebaldi@ufu.br)

Data da submissão:10/05/2018. Aceito para publicação em: 19/12/2019
\end{abstract}

$10.1590 / 0100-5405 / 198561$

\section{RESUMO}

Mamede, M.C.; Tebaldi, N.D. Detecção de Pantoea ananatis em sementes de milho. Summa Phytopathologica, v.46, n.1, p.36-40, 2020.

A cultura milho (Zea mays L.) está sujeita a ocorrência de várias doenças, entre elas a mancha branca, causada pela bactéria Pantoea ananatis. Recentemente a bactéria foi detectada em sementes de milho. Diante disso, este trabalho teve como objetivos: avaliar meios de cultura para detecção de $P$. ananatis, detectar a presença da bactéria em oito genótipos de sementes milho, identificar e caracterizar bioquímica e molecularmente os isolados bacterianos obtidos. Para avaliação dos meios de cultura, o isolado de $P$. ananatis foi cultivado em cinco meios de cultura (523, NA, TSA, PA10 e PA20) com ausência e presença dos fungicidas ciclohexamida e tiofanato metílico, com três repetições cada. A eficiência de cada meio de cultura foi determinada a partir do diâmetro das colônias e contagem do número de colônias em UFC $\mathrm{mL}^{-1}$. Para detecção da bactéria em sementes, oito genótipos de milho foram avaliados. Os extratos das sementes foram diluídos em série $\left(10^{-1}\right.$ a $\left.10^{-2}\right)$ e cultivados em três meios de cultura (523, NA e TSA) com três repetições para cada diluição. Os isolados obtidos foram caracterizados bioquímica, fisiologicamente e molecularmente. Os meios de cultura TSA e $523 \mathrm{com}$ adição de ciclohexamida foram eficientes para a detecção de $P$. ananatis. A bactéria foi detectada em cinco genótipos de sementes de milho. O meio de cultura TSA com adição de ciclohexamida pode ser recomendado para a detecção de $P$. ananatis em sementes de milho.

Palavras-chave: Etiologia; Mancha branca; Meio de cultura; Zea mays.

\section{ABSTRACT}

Mamede, M.C.; Tebaldi, N.D. Detection of Pantoea ananatis in corn seeds. Summa Phytopathologica, v.46, n.1, p.36-40, 2020.

The corn (Zea mays L.) crop is subject to the occurrence of several diseases, including white spot, caused by Pantoea ananatis. Recently, this bacterium has been detected in corn seeds. Thus, the objectives of this study were: to evaluate culture media for $P$. ananatis detection, to detect this bacterium in eight corn seed genotypes, and to identify and biochemically and molecularly characterize the obtained bacterial isolates. To evaluate the culture media, the isolate of $P$. ananatis was cultivated in five culture media (523, NA, TSA, PA10 and PA20) with absence and presence of the fungicides cycloheximide and thiophanatemethyl, and three replicates each. The efficiency of each culture medium was determined based on the diameter of colonies and on the counting of colonies as $\mathrm{CFU} \mathrm{mL} \mathrm{m}^{-1}$. To detect the bacterium in seeds, eight corn genotypes were evaluated. Seed extracts underwent serial dilution $\left(10^{-1}\right.$ to $\left.10^{-2}\right)$ and were grown in three culture media (523, NA and TSA) with three replicates for each dilution. The obtained isolates were biochemically, physiologically and molecularly characterized. The culture media TSA and 523 with addition of cycloheximide were effective in detecting $P$. ananatis. This bacterium was detected in five corn seed genotypes. TSA with addition of cycloheximide can be recommended for $P$. ananatis detection in corn seeds.

Keywords: Etiology; white spot; culture medium; Zea mays.

A cultura do milho (Zea mays L.) está sujeita a ocorrência de várias doenças, entre elas a mancha branca, causada pela bactéria Pantoea ananatis (15). A doença possui ampla distribuição geográfica, acarretando perdas de $60 \%$ na produção $(22,27)$, principalmente em plantios de segunda safra, devido temperatura moderada e alta umidade relativa, favoráveis para o desenvolvimento da doença (3).

A bactéria sobrevive epifiticamente em folhas de milho, em restos culturais (23), em folhas de sorgo, capim colchão (7), capim carrapicho e caruru (12), sendo portanto, fontes de inóculo da bactéria no campo.

A detecção e a transmissão de $P$. ananatis já foram descritas em sementes de cebola (3) e recentemente, Mamede et al. (9) detectaram a bactéria em sementes de milho, utilizando meio de cultura semiseletivo (PA 20).
No manejo da doença recomenda-se o uso de genótipos resistentes, a aplicação de fungicidas (16) que, no entanto, não é eficiente (19) e o uso de sementes livres do patógeno, para evitar a disseminação e introdução da bactéria em novas áreas de cultivo.

As bactérias fitopatogênicas podem ser detectadas em sementes pelo uso de meios de cultura semi-seletivos que ofereçam alta sensibilidade, confiabilidade e rapidez dos resultados (28). Meios de cultura semi-seletivos já foram descritos para a detecção de Xanthomonas axonopodis pv. malvacearum em sementes de algodão $(25,30)$, Xanthomonas campestris pv. campestris em sementes de brócolis (26) e de Xanthomonas axonopodis pv. glycines em sementes de soja (29).

Dessa forma, os meios de cultura são alternativa possível de adoção 
em análise de rotina em laboratório, para a detecção de bactérias em sementes.

Diante disso, os objetivos deste trabalho foram avaliar meios de cultura para detecção de $P$. ananatis, detectar a bactéria em sementes de oito genótipos de milho e identificar, caracterizar bioquímica e molecularmente os isolados bacterianos obtidos.

\section{MATERIAL E MÉTODOS}

Os experimentos foram conduzidos no Laboratório de Bacteriologia Vegetal (LABAC), do Instituto de Ciências Agrárias (ICIAG), da Universidade Federal de Uberlândia (UFU).

\section{Preparo da suspensão bacteriana}

O isolado bacteriano UFU B13, de Pantoea ananatis pertencente à coleção de trabalho do LABAC, do ICIAG, da UFU foi recuperado e multiplicado em meio de cultura 523 (5) por $24-48$ horas a $28{ }^{\circ} \mathrm{C}$.

A suspensão bacteriana foi preparada em água filtrada esterilizada, ajustada em espectrofotômetro para $\mathrm{OD}_{550}=0,1$ correspondendo

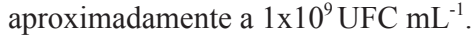

\section{Meios de cultura para deteç̧ão de Pantoea ananatis}

A suspensão bacteriana foi diluída em série $\left(10^{-1}\right.$ a $\left.10^{-7}\right)$ e cultivada sobre cinco meios de cultura 523, NA, PA20 (4), PA10 (diferindo de PA20, pela adição de $10 \mathrm{~g}$ de $\mathrm{NaCl}$ ) e TSA, sem e com adição dos fungicidas tiofanato metílico $0,04 \mathrm{mg} \mathrm{mL}^{-1}$ (1) ou de ciclohexamida $0,005 \mathrm{mg} \mathrm{mL}^{-1}$. As placas foram incubadas em BOD a $28{ }^{\circ} \mathrm{C}$ por até dez dias.

A eficiência de cada meio de cultura foi determinada a partir do diâmetro e pela contagem do número de colônias em UFC $\mathrm{mL}^{-1}$.

$\mathrm{O}$ experimento foi realizado em esquema fatorial ( 5 meios de cultura x 3 ausência e presença de 2 fungicidas), com três repetições e as médias comparadas pelo teste de Tukey a $5 \%$ de probabilidade.

\section{Detecção de Pantoea ananatis em sementes de milho}

Para a detecção da bactéria Pantoea ananatis em sementes foram avaliados oito genótipos de milho: ADV 9339; ADV 9275 Pro; ADV 9860 Pro; Morgan MG 600 PW; 30F53HY; 30A37PW e dois genótipos codificados de Formosa (GO), provenientes de plantas com sintomas de mancha branca.

Em Erlenmeyer foram adicionados $100 \mathrm{~g}$ de sementes e $200 \mathrm{~mL}$ de água filtrada esterilizada, incubados em geladeira por 16 horas. Os extratos de sementes foram diluídos em série $\left(10^{-1}\right.$ a $\left.10^{-2}\right)$ e cultivados nos meios de cultura 523, NA e TSA com adição de ciclohexamida, em placas de Petri, com três repetições para cada diluição. As placas foram incubadas a $28{ }^{\circ} \mathrm{C}$ por $\leqslant$ dias, calculando-se o número de UFC $\mathrm{g}^{-1}$ de sementes.

As colônias suspeitas foram repicadas e cultivadas em meio 523 e caracterizadas bioquímica e fisiologicamente, pelos testes de Gram, Oxidação/Fermentação, YDC, motilidade, produção de ácidos a partir da glicose de inositol, sorbitol, sacarose e D-arabinose, pela produção das enzimas arginina dihidrolase, liquefação da gelatina, oxidase, catalase e crescimento a $37{ }^{\circ} \mathrm{C}$ e reação de hipersensibilidade em plantas de fumo.

Para o teste de patogenicidade, plantas de milho da cultivar Morgan MG 600 PW foram cultivadas em 5 vasos plásticos de capacidade de $500 \mathrm{~g}$, com 2 plantas por vaso. A inoculação foi realizada pela pulverização da suspensão bacteriana, quando as plantas apresentavam de 3 a 4 folhas. As plantas foram mantidas em câmara úmida 24 horas antes e após a inoculação. A partir do aparecimento dos sintomas (lesões encharcadas progredindo para necrose do tecido) foi realizado reisolamento da bactéria.

A caracterização molecular foi realizada utilizando um par de primers ANAF: (5'-CGTGAAACTACCCGTGTCTGTTGC-3') e ANAR: (5'-TGCCAGGGCATCCACCGTGTACGCT-3') (4, 17), específicos para Pantoea ananatis.

Dez isolados bacterianos obtidos na detecção em sementes, com características bioquímicas de $P$. ananatis, foram utilizados na reação em cadeia da polimerase (PCR). O DNA foi extraído usando o KitPROMEGA (Wizard Genomic DNA Purification Kit) e quantificado no Thermo Scientific ${ }^{\mathrm{TM}}$ Nanodrop 2000/2000c Spectrophotometer. As reações de PCR foram realizadas em um volume final de $12,5 \mu \mathrm{L}$ de reação, contendo 1x Tampão de PCR10X com $\mathrm{Mg}^{+2}$; 0,2mM dNTP; $2 \mu \mathrm{M}$ primer ANAF e ANAR; $1 \mathrm{U}$ Taq Polimerase; 50ng DNA genômico. A amplificação foi realizada em termociclador ThermoHybaid: Omn-E com as seguintes condições: um ciclo para desnaturação do DNA a 94 ${ }^{\circ} \mathrm{C}$ por $1 \mathrm{~min}, 30$ ciclos de $1 \mathrm{~min}$ a $94{ }^{\circ} \mathrm{C}, 1 \mathrm{~min}$ a $68^{\circ} \mathrm{C}$ (anelamento) e 1 min a $72{ }^{\circ} \mathrm{C}$ (extensão), e um ciclo final de 10 min a $72^{\circ} \mathrm{C}$. Os produtos de amplificação foram analisados por eletroforese em gel de agarose a 1,0\%, corados com SYBR Safe e visualizados sob luz ultravioleta e fotografados.

\section{RESULTADOS E DISCUSSÃO}

\section{Meios de cultura para detecção de Pantoea ananatis}

No meio TSA (Tabela 1), sem adição de fungicidas, o diâmetro da colônia foi de $4,93 \mathrm{~mm}$, diferindo significativamente dos demais meios de cultura. Quando houve adição de ciclohexamida, não houve diferença significativa entre os meios $523(2,90)$ e TSA $(3,10)$. No entanto, com a adição de tiofanato metílico o diâmetro da colônia foi

Tabela 1. Diâmetro (mm) de colônias de Pantoea ananatis em diferentes meios de cultura, sem e com adição de fungicidas. Uberlândia - MG.

\begin{tabular}{lccc} 
Meio de cultura & Sem fungicida & Ciclohexamida & Tiofanato metílico \\
\hline PA10 & $0,00 \mathrm{Ad}$ & $0,00 \mathrm{Ac}$ & $0,00 \mathrm{Ad}$ \\
PA20 & $0,00 \mathrm{Ad}$ & $0,00 \mathrm{Ac}$ & $0,00 \mathrm{Ad}$ \\
NA & $1,02 \mathrm{Ac}$ & $1,00 \mathrm{Ab}$ & $1,02 \mathrm{Ac}$ \\
523 & $1,96 \mathrm{Bb}$ & $2,90 \mathrm{Aa}$ & $3,00 \mathrm{Aa}$ \\
TSA & $4,93 \mathrm{Aa}$ & $3,10 \mathrm{Ba}$ & $2,15 \mathrm{Cb}$ \\
\hline CV\% & 6,49 & & \\
\hline
\end{tabular}

Médias seguidas por letras distintas, maiúsculas na linha e minúsculas na coluna diferem entre si, pelo teste de Tukey a 0,05. 


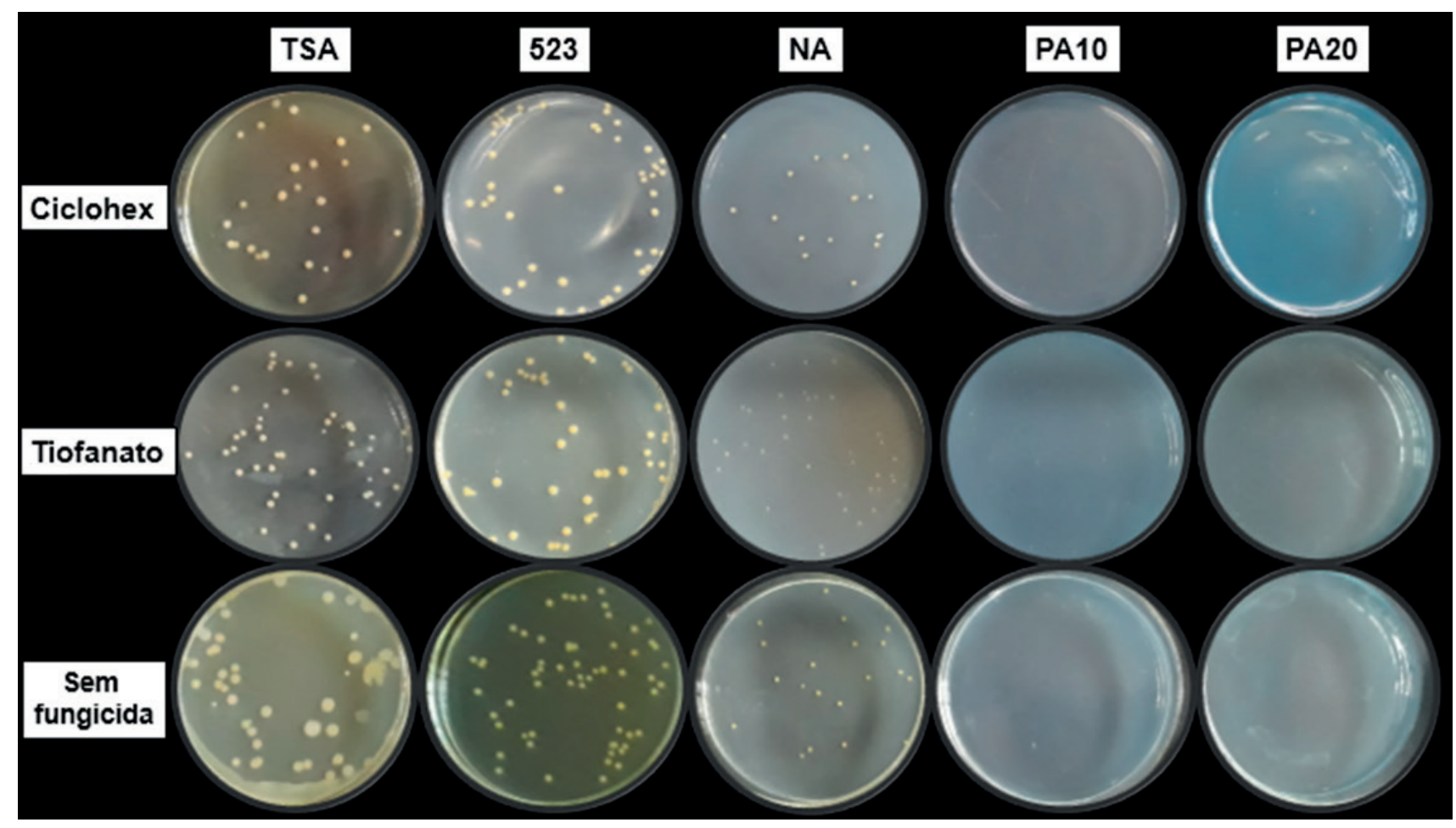

Figura 1. Pantoea ananatis em meio de cultura TSA, 523, NA, PA10 e PA20 com adição de ciclohexamida; tiofanato metílico e sem fungicida.

maior no meio $532(3,00)$, diferindo significativamente do meio do TSA $(2,15)$. Nos meios PA 10 e PA 20, sem e com adição de fungicidas, não foi possível o crescimento bacteriano. A adição de cicloheximida e tiofanto metílico aos meios de cultura 523 e TSA, proporcionaram um aumento e diminuição do diâmetro das colônias, respectivamente.

Nos meios de cultura TSA e 523 (Figura 1), sem e com a adição de fungicidas, as colônias de $P$. ananatis apresentaram maior diâmetro, após o quarto dia do seu cultivo e nos meios PA10 e PA20 não houve crescimento bacteriano.

O uso de fungicidas associado aos meios de cultura, além de reduzir o número de microrganismos contaminates, também pode favorecer o desenvolvimento da espécie desejada (22). Este foi um fato constatado no ensaio, pois no meio de cultura 523, a adição dos fungicidas levou a um aumento no tamanho das colônias, já no caso do meio TSA os fungicidas reduziram (Tabela 1) o diâmetro da colônia, porém sem prejuízo a sua visualização.

Diversas são as metodologias disponíveis para diagnóstico adequado de problemas fitossanitários, o que torna os resultados complementares e a análise mais acurada (10). O plaqueamento em meios de cultura semi-seletivo têm sido utilizado para detectar e acessar a viabiliade de bactérias (2). Entretanto, a inclusão de compostos antibióticos e antifúngicos ao meio básico para a inibição de saprófitas deve ser estudada cuidadosamente, visto que a mínima sensibilidade a estes compostos pode prejudicar a recuperação das bactérias alvo (18).

Na elaboração de um meio de cultura semi-seletivo, a ausência de repressividade e supressividade elevada são características desejadas, no entanto quase nem sempre é alcançado (8). Ainda que sejam escolhidos apenas agentes de seletividade que não prejudiquem os microrganismos alvos, a mistura destes ao meio de cultura pode causar efeito negativo. Na recuperação de Xanthomonas axonopodis pv. vitians foi observado menor crescimento das colônias no meio seletivo desenvolvido (MMG) quando comparado a um meio não seletivo (28).
Neste estudo, os meios semi-seletivos PA 20 e PA 10 exibiram colônias apenas 10 dias após a realização do ensaio. Diante disso, estes meios de cultura não são recomendados para a detecção de bactérias em sementes, já que busca-se métodos que apresentem sensibilidade, especificidade, precisão e rapidez nos resultados (28).

Para o número de colônias desenvolvidas, não houve diferença significativa entre os meios de cultura 523 e TSA (Tabela 2), aos quatro dias do cultivo da bactéria. O meio de cultura NA não diferiu significativamente do meio 523, no número de colônias desenvolvidas. No entanto, para os meios PA 10 e PA 20 não houve detecção da bactéria. A presença dos fungicidas ciclohexamida e tiofanato metílico (Tabela 3) não diferiram significativamente entre si, no crescimento da bactéra, ou seja, o uso destes fungicidas não inibiram o crescimento bacteriano. Portanto, estes fungicidas podem ser incorporados aos meios de cultura, para facilitar a detecção da bactéria alvo e inibir o crescimento de microrganismos saprófitas.

Nos meios PA 20 e PA 10 o crescimento da bactéria foi observado somente ao décimo dia após o cultivo, com colônias menores que $1 \mathrm{~mm}$.

Tabela 2. Detecção de Pantoea ananatis em diferentes meios de cultura, em unidades formadoras de colônia. Uberlândia - MG.

\begin{tabular}{lc}
\hline Meio de cultura & UFC $\mathbf{~ m L}^{-1}$ \\
\hline PA10 & $0,00 \mathrm{c}$ \\
PA20 & $0,00 \mathrm{c}$ \\
NA & $3,4 \times 10^{9} \mathrm{~b}$ \\
523 & $4,5 \times 10^{9} \mathrm{ab}$ \\
TSA & $5,2 \times 10^{9} \mathrm{a}$ \\
\hline CV\% & 38,55 \\
\hline
\end{tabular}

Médias seguidas por letras distintas diferem pelo teste de Tukey a 0,05. 
Tabela 3. Detecção de Pantoea ananatis na ausência e presença de fungicidas, em unidades formadoras de colônia. Uberlândia - MG.

\begin{tabular}{lc}
\hline Tratamento & UFC $\mathbf{~ m L}^{-1}$ \\
\hline Sem fungicida & $2,1 \times 10^{9} \mathrm{~b}$ \\
Ciclohexamida & $2,7 \times 10^{9} \mathrm{ab}$ \\
Tiofanato metílico & $3,0 \times 10^{9} \mathrm{a}$ \\
\hline $\mathrm{CV} \%$ & 38,55 \\
\hline
\end{tabular}

Médias seguidas por letras distintas diferem pelo teste de Tukey a 0,05 .

Mamede et al. (9) observaram que no meio semi-seletivo PA20 houve redução no diâmetro das colônias quando comparado ao meio 523. Esse comportamento, deve-se a redução do $\mathrm{pH}$ do meio promovida pela $P$. ananatis devido a degradação do arabitol em ácido (4).

A redução do diâmetro das colônias também foi observada na detecção de Xanthomonas axonopodis pv. glycines no meio semiseletivo MXG (29) e na detecção de Xanthomonas axonopodis pv. vignicola em videira no meio CCM (17).

A seletividade dos meios de cultura pode ser obtida através de fontes específicas de carbono e nitrogênio, as quais buscam estimular o crescimento de uma determinada espécie e inibir outra. A adição de substâncias tóxicas visa reduzir o número de contaminantes e favorecer o desenvovimento da espécie desejada (13).

Embora não houvesse crescimento de microrganismos oportunistas nos meios de cultura PA10 e PA20, mesmo sem a adição dos fungicidas, o crescimento da bactéria alvo foi prejudicado. A diminuição do tamanho das colônias, bem como a demora em seu crescimento podem ter relação com a presença de $\mathrm{NaCl}$ (cloreto de sódio), considerado uma susbstância inibidora. Tortora et al. (27) descrevem que altas concentrações de $\mathrm{NaCl}$ tornam o ambiente hipertônico, o que leva a perda de água da célula com consequente entrave do crescimento da bactéria.

Dessa forma, verificou-se que os meios TSA e 523, com adição de ciclohexamida ou tiofanato metílico, podem ser recomendados para a detecção da bactéria em análise de rotina em laboratório, já que apresentaram alta eficiência no crescimento de $P$. ananatis e supressividade satisfatório.

\section{Detecção de Pantoea ananatis em sementes de milho}

A bactéria foi detectada em sementes de cinco, dos oitos genótipos avaliados (Tabela 4). Nos meios de cultura 523, NA e TSA a bactéria foi detectada em sementes de milho dos genótipos ADV 9860 Pro e Genótipo 2. Para o meio de cultura NA a bactéria foi detectada na semente do genótipo ADV 9275 Pro. E para o meio de cultura TSA a bactéria foi detectada nas sementes do genótipo 30A37PW e Genótipo 1. Destacando que no meio de cultura TSA houve a detecção da bactéria em sementes de quatro genótipos de milho avaliados, em UFC g de semente ${ }^{-1}$.

A alta taxa de recuperação observada nas amostras de sementes reflete a baixa repressividade dos meios desenvolvidos (523, NA e TSA com adição de ciclohexamida). Resultados semelhantes foram observados na deteç̧ão de Xanthomonas campestris pv. campestris em sementes de brócolis (26), na detecção de Curtobacterium flaccumfaciens pv. flaccumfaciens em sementes de feijoeiro (11), na recuperação de Burkholderia glumae em sementes de arroz (6), na detecção de Xanthomomas campestris em sementes de girassol (20), na detecção de Xanthomonas axonopodis pv. phaseoli em sementes de feijoeiro (21).
Tabela 4. Médias da detecção de Pantoea ananatis em sementes, de diferentes genótipos de milho, nos meios de cultura 523, NA e TSA, com adição de ciclohexamida. Uberlândia - MG

\begin{tabular}{lccc}
\hline \multirow{2}{*}{ Genótipos } & \multicolumn{3}{c}{ Meios de cultura (UFC g de semente $^{-1}$ ) } \\
\cline { 2 - 4 } & $\mathbf{5 2 3}$ & NA & TSA \\
\hline ADV 9339 & 0,00 & 0,00 & 0,00 \\
ADV 9275 Pro & 0,00 & 6,67 & 0,00 \\
ADV 9860 Pro & 20,00 & 48,89 & 162,22 \\
Morgan MG 600 PW & 0,00 & 0,00 & 0,00 \\
30F53HY & 0,00 & 0,00 & 0,00 \\
30A37PW & 0,00 & 0,00 & 666,67 \\
Genótipo 1 & 4,44 & 0,00 & 24,44 \\
Genótipo 2 & 133,33 & 222,22 & 151,11 \\
\hline
\end{tabular}

Apesar dos lotes de sementes serem coletados de áreas com histórico de mancha branca, nos genótipos ADV 9339, Morgan MG 600 PW e 30F53HY, não houve a detecção de $P$. ananatis.

Todos os dez isolados bacterianos detectados nas sementes de milho foram caracterizados como: Gram negativos, fermentação da glicose, colônias amarelas em meio YDC, oxidase negativa, catalase positiva, arginina dihidrolase positiva, produção de ácidos a partir do inositol, sorbitol, sacarose, D-arabinose todos positivo, motilidade positivo, liquefação da gelatina positivo, crescimento a $37^{\circ} \mathrm{C}$ positivo e reação de hipersensibilidade em fumo positivo.

Os isolados bacterianos obtidos das sementes foram patogênicos em plantas de milho, sendo que no segundo dia após a inoculação foi possível observar a reprodução dos sintomas de lesões encharcadas características da mancha-branca em plantas de milho, cultivadas em casa de vegetação. A partir do aparecimento das lesões necróticas foi realizado o reisolamento da bactéria, confirmando os Postulados de Koch.

Os primers ANAF/ANAR, específicos para $P$. ananatis, confirmaram a identidade dos isolados bacterianos, gerando um fragmento de DNA de tamanho aproximado de 380 pb, em concordância com Miller (14).

De acordo com os testes para caracterização bioquímica, fisiológica, morfológica, molecular, e patogenicidade no hospedeiro a bactéria foi identificada como Pantoea ananatis.

Apesar da taxa de transmissão de bactérias por sementes ser baixa (24), a utilização de sementes contaminadas com $P$. ananatis poderá resultar em plantas infectadas e a introdução do patógeno em campos de produção, que sob condições favoráveis de temperatura e umidade, leva a rápida disseminação, causando sérios prejuízos as lavouras. Assim é evidente a utilização de meios de cultura para a detecção da bactéria em sementes, devido a sua importância na cultura do milho.

O meio de cultura TSA com adição de cicloheximida foi eficiente para detecção da bactéria $P$. ananatis em sementes de milho, podendo ser usado em análises de rotina em laboratório.

\section{REFERÊNCIAS}

1. Bomfeti, C. A.; Meirelles, W. F.; Souza-Paccola, E. A.; Casela, C. R.; Ferreira, A. S.; Marriel, I. E.; Paccola-Meirelles, L. D. Avaliação de produtos químicos comerciais, in vitro e in vivo, no controle da doença foliar, mancha branca do milho, causada por Pantoea ananatis. Summa Phytopathologica, 
Botucatu, v. 33, p. 63-67, 2007.

2. Chang, C. J.; Donaldson, R.; Crowley, M.; Pinnow, D. A new semiselective medium for the isolation of Xanthomonas campestris pv. campestris from crucifer seeds. Phytopathology, St. Paul, v. 81, p. 449-453, 1990.

3. Goszczynska, T.; Moloto, V. M.; Venter, S. N.; Coutinho, T. A. Isolation and identification of Pantoea ananatis from onion seed in South Africa. Seed Science \& Technology, Zurich, v. 34, p. 677-690, 2006 a.

4. Goszczynska, T.; Venter, S. N.; Coutinho, T. A. PA 20, a semi-selective medium for isolation and enumeration of Pantoea ananatis. Journal of Microbiological Methods, Amsterdam, v. 64, p. 225-231, 2006b.

5. Kado, C. I.; Heskett, M. G. Selective media for isolation of Agrobacterium, Corynebacterium, Erwinia, Pseudomonas and Xanthomonas. Phytopathology, Saint Paul, v. 60, p. 969-976, 1970.

6. Kawaradani, M.; Okada, K.; Kusakari, S. New selective medium for isolation of Burkholderia glumae from rice seeds. Journal of General Plant Pathology, Toquio, v. 66, p. 234-237, 2000.

7. Lana, U. G. P.; Gomes, E. A.; Silva, D. D.; Costa, R. V.; Cota, L. V.; Parreira, D. F.; Souza, I. R. P.; Guimarães, C. T. Detection and molecular diversity of Pantoea ananatis associated with White Spot Disease in Maize, Sorghun and Crabgrass in Brasil. Journal of Phytopathology, Berlin, v. 160, p. 441-448, 2012.

8. Lopes, L.P.; Alves, P. F. R.; Zandoná, C.; Nunes, M. P.; Meht, Y. R. Meio semi-seletivo para detectar Xanthomonas axonopodis pv. phaseoli em sementes de feijoeiro e sua erradicação através do tratamento de sementes com o fungicida tolylfluanid. Summa Phytopathologica, Botucatu, v. 34, p. 287-288, 2008.

9. Mamede, M. C.; Tebaldi, N. D.; Mota, L. C. B. M.; Martins, O. M.; Coelho, L. Detection of Pantoea ananatis in corn seeds on semi-selective medium Tropical Plant Pathology, Switzerland, v. 43, n.3, p. 254-256, 2018. DOI: https://doi.org/10.1007/s40858-017-0203-z. Disponível em: https://link.springer.com/article/10.1007\%2Fs40858-017-0203-z. Acesso em: março 2018.

10. Marques, A. S. A.; Corbière, R.; Gardan, L.; Tourte, C.; Manceau, C.; Taylor, J. D.; Samson, R. Multiphasic approach for the identification of the different classification levels of Pseudomonas savastanoi pv. phaseolicola. European Journal of Plant Pathology, Oxford, v. 106, p. 715-734, 2000.

11. Maringoni, A. C.; Camara, R. C. Curtobacterium flaccumfaciens pv. flaccumfaciens detection in bean seeds using a semi-selective culture médium. Brazilian Journal of Microbiology, São Paulo, v. 37, p. 451-455, 2006.

12. Martins, A. A. Hospedeiros alternativos de Pantoea ananatis. 2014. 28 f. Trabalho de Conclusão de Curso (Graduação em Agronomia) - Universidade Federal de Uberlândia, Uberlândia.

13. Mcguire, R. G.; Jones, J. B.; Sasser, M. Tween media for semi selective isolation of Xanthomonas campestris pv. vesicatoria from soil and plant material. Plant Disease, Saint Paul, v. 70, p. 887-891, 1986.

14. Miller, A. M. Variabilidade genética e nucleação de gelo em isolados de Pantoea ananatis, agente causal da mancha branca do milho. 2014. 73 f. Dissertação (Mestrado em Agronomia) - Universidade Estadual de Londrina, Londrina.
15. Paccola-Meirelles, L. D.; Ferreira, A. S.; Meirelles, W. F.; Marriel, I. E.; CaseC la, C. R. Detection of bacterium associated with a leaf spot disease of maize in Brazil. Journal of Phytopathology, Berlin, v.149, p. 275-279, 2001.

16. Pedro, E. S.; Gonçalves, R. M.; Meirelles, W. F.; Regina, M.; Paccola-Meirelles, L. D. Avaliação de diferentes produtos no controle da mancha branca do milho. In: Congresso Nacional de Milho e Sorgo, 28., 2010, Goiânia: Associação Brasileira de Milho e Sorgo, 2010. 1 CD-ROM.

17. Peixoto, A. R.; Mariano, R. L. R.; Viana, I. O. Meio semi seletivo para isolamento de Xanthomonas campestris pv. vignicola. Ciência Rural, Santa Maria, v. 36, p. 1317-1320, 2006.

18. Randhawa, P. S.; Schaad, P. Selective isolation of Xanthomonas campestris pv. campestris from crucifer seed. Phytopathology, St. Paul, v. 74, p. 268-272, 1983.

19. Romeiro, R. S. Bactérias fitopatogênicas. 2. ed. Viçosa: UFV, 2005. 417 p.

20. Romeiro, R. S.; Moura, A. B.; Monteiro, A. J. A bioassay for detection and quantification of Xanthomonas campestris in sunflower seeds. Seeds Technology, Lincoln, v. 20, p. 94-99, 1998.

21. Romeiro, R. S.; Peres, F.; Oliveira, J. R.; Del Peloso, M. J. Detecção de Xanthomonas campestris pv. phaseoli em sementes de feijoeiro: quantificação e percentage de transmissão. Revista Brasileira de Sementes, Brasília, DF, v. 15, p. 1-5, 1993.

22. Roumagnac, P.; Gagnevin, L. E Pruvost, O. Detection of Xanthomonas sp., the causal agent of onion bacterial blight, in onion seeds using a newly developed semi-selective isolation medium. European Journal of Plant Pathology, Switzerland, v. 106, p. 867-877, 2000

23. Sauer, A. V.; Figueiredo, J. E. F.; Baba, V. Y.; Pedro, E. S.; Meirelles, W. F.; Paccola-Meirelles, L. D. Sobrevivência de Pantoea ananatis, agente causal da mancha branca do milho, em restos culturais de milho. In: Congresso Nacional de Milho e Sorgo, 28., 2010, Goiânia: Associação Brasileira de Milho e Sorgo, 2010. 1 CD-ROM.

24. Schaad. N. W. Detection of Xanthomonas campestris pv. campestris in crucifers. In: Saettler, A. W.; Schaad, N. W.; Roth, D. A. Detection of bacteria in seed and other planting material. St. Paul: APS Press, 1989, p. 68-75.

25. Soares, J. Desenvolvimento de meio semi-seletivo para detecção de Xanthomonas axonopodis pv. malvacearum em sementes de algodoeiro. 2006. 57 f. Dissertação (Mestrado em Fitopatologia) - Universidade de Passo Fundo, Passo Fundo.

26. Tebaldi, N. D; Panizzi, R. C.; Sader, R. Detecção, transmissão e efeito de Xanthomonas campestris pv. campestris na qualidade fisiológica de sementes de brócolis. Summa Phytopathologica, Botucatu, v. 33, p. 416-418, 2007.

27. Tortora, G. J.; Funke, B. R.; Case, C. L. Microbiologia. 12. Ed. Porto Alegre: Artmed, 2017. 964 p.

28. Toussaint, V.; Morris, C. E.; Carisse, O. A new semi-selective medium for Xanthomonas campestris pv. vitians, the causal agent of bacterial leaf spot of lettuce. Plant Disease, Saint Paul, v. 85, p. 131-136, 2001.

29. Violatti, M. R.; Tebaldi, N. D. Detecção de Xanthomonas axonopodis pv. glycines em sementes de soja. Summa Phytopathologica, Botucatu, v. 42 , p. $268-270,2016$

30. Zachowski, M. A.; Rudolph, K. Characterization of isolates of bacterial blight of cotton (Xanthomonas campestris pv. malvacearum) from Nicaragua. Journal of Phytopathology, Berlin, v. 123, p. 344-352, 1988. 